\title{
Treating PTSD in refugees and asylum seekers within the general health care system. A randomized controlled multicenter study ${ }^{\text {is }}$
}

\author{
Håkon Stenmark ${ }^{\mathrm{a}, \mathrm{b}, *}$, Claudia Catani $^{\mathrm{c}}$, Frank Neuner ${ }^{\mathrm{c}}$, Thomas Elbert ${ }^{\mathrm{e}}$, Are Holen $^{\mathrm{a}, \mathrm{d}}$ \\ ${ }^{a}$ Dept. of Neuroscience, Norwegian University of Science and Technology, 7489 Trondheim, Norway \\ ${ }^{\mathrm{b}}$ Centre on Violence, Traumatic Stress and Suicide Prevention, Mid-Norway, St. Olav University Hospital, Schwacks Gt. 1, 7030 Trondheim, Norway \\ ${ }^{\mathrm{c}}$ Dept. of Psychology, University of Bielefeld, 33501 Bielefeld, Germany \\ d St. Olav University Hospital, 7030 Trondheim, Norway \\ ${ }^{\mathrm{e}}$ Dept. of Psychology, University of Konstanz, 78457 Konstanz, Germany
}

Keywords:

Refugee

Asylum seeker

PTSD

Treatment

Narrative Exposure Therapy

Randomized controlled trial

\begin{abstract}
A B S T R A C T
Objective: There has been uncertainty about whether refugees and asylum seekers with PTSD can be treated effectively in standard psychiatric settings in industrialized countries. In this study, Narrative Exposure Therapy (NET) was compared to Treatment As Usual (TAU) in 11 general psychiatric health care units in Norway. The focus was on changes in symptom severity and in the diagnostic status for PTSD and depression.

Method: Refugees and asylum seekers fulfilling the DSM IV criteria for PTSD $(N=81)$ were randomized with an a priori probability of $2: 1$ to either NET $(N=51)$ or TAU $(N=30)$. The patients were assessed with Clinician Administered PTSD Scale, Hamilton rating scale for depression and the MINI Neuropsy chiatric Interview before treatment, and again at one and six months after the completion.

Results: Both NET and TAU gave clinically relevant symptom reduction both in PTSD and in depression. NET gave significantly more symptom reduction compared to TAU as well as significantly more reduction in participants with PTSD diagnoses. No difference in treatment efficacy was found between refugees and asylum seekers.

Conclusions: The study indicated that refugees and asylum seekers can be treated successfully for PTSD and depression in the general psychiatric health care system; NET appeared to be a promising treatment for both groups.
\end{abstract}

\section{Introduction}

Several studies have shown that migrants who fled from war and persecution in their home countries reported high rates of pre migration trauma and high frequencies of trauma related mental health problems (Porter \& Haslam, 2005; Sinnerbrink, Silove, Field, Steel, \& Manicavasagar, 1997; Turner, Bowie, Dunn, Shapo, \& Yule, 2003). PTSD and depression appeared as the most common

\footnotetext{
is The work was done by the Centre on Violence, Traumatic Stress and Suicide Prevention, Mid-Norway, St. Olav University Hospital, Trondheim, Norway.

* Corresponding author. Centre on Violence, Traumatic Stress and Suicide Prevention, Mid-Norway, St. Olav University Hospital, Schwacks Gt. 1, 7030 Trondheim, Norway. Tel.: +47 90862914; fax: +47 73861260 .

E-mail addresses: hakon.stenmark@stolav.no (H. Stenmark), claudia.catani@unibielefeld.de (C. Catani), frank.neuner@uni-bielefeld.de (F. Neuner), thomas.elbert@unikonstanz.de (T. Elbert), are.holen@ntnu.no (A. Holen).
}

mental conditions (Fazel, Wheeler, \& Danesh, 2005; Steel et al., 2009). Forced migrants can broadly be divided into two cate gories. Those who have been granted asylum in their new coun tries, commonly referred to as refugees, and the asylum seekers who live with the uncertainty of having their applications rejected and thus may be returned to their countries of origin (Toar, O'Brien, \& Fahey, 2009). PTSD and depression symptoms in asylum seekers seem far more pronounced than in refugees. This may be due to post migratory stresses including delays in the application process, conflicts with immigration officials, denial of work permits, un employment, separation from families, loneliness and boredom (Toar et al., 2009). Concurrent stress and lack of social support in the new countries environment may increase the depressive symptoms and come in addition to their traumatic stress experi ences of the past (Gorst Unsworth \& Goldenberg, 1998). The pres sures may increase over time, particularly if asylum seekers live under harsh conditions (Steel et al., 2011). 
High levels of exposure to traumatic and other major stressors have brought many refugees and asylum seekers into contact with the psychiatric services. However, it has been debated how well refugees and asylum seekers respond to treatment in the regular Western psychiatric settings. Some studies of torture victims have questioned the efficacy of treatment (Birck, 2001, 2004; Carlsson, Mortensen, \& Kastrup, 2005). Others (Hinton et al., 2005; Otto et al., 2003; Paunovic \& Ost, 2001) have indicated that trauma focused cognitive behavioural therapy is effective for refugees with posttraumatic symptoms. However, these studies have been criti cised for low power and selected samples.

Narrative Exposure Therapy (NET) is a relatively new psycho therapeutic approach (Schauer, Neuner, \& Elbert, 2005). It aims to treat PTSD after war experiences and torture. In NET, the patients are assisted to construct a chronological narrative of their life stories with special emphasis in the traumatic experiences. Active listening and empathic understanding are key elements in the therapist's efforts to transform fragmented reports of traumas into coherent narratives. The patients are encouraged to relive the events and allow cognitive and affective responses while narrating without loosing the realisation that the memories are of the past. Therapeutic re exposures to traumatic experiences are not termi nated before the associated fear responses show significant decline.

Randomized controlled trials of refugees residing in Uganda, Sri Lanka and Rwanda indicate that NET reduces trauma related symptom levels even under insecure living conditions in patients who only have the most basic accommodation (Catani et al., 2009; Ertl, Pfeiffer, Schauer, Elbert, \& Neuner, 2011; Neuner, Schauer, Klaschik, Karunakara, \& Elbert, 2004; Schaal, Elbert, \& Neuner, 2009). Also, pilot studies have indicated that NET can help refu gees and asylum seekers in the Western countries (Halvorsen \& Stenmark, 2010; Neuner et al., 2009).

In a recent review of psychological PTSD treatments for refu gees, Nickerson, Bryant, Silove \& Steel (Nickerson, Bryant, Silove, \& Steel, 2011) pointed to the scarcity of high quality treatment studies. A critical stance was taken towards the fact that studies so far had been carried out at university settings or at specialized treatment centres. The authors' two main recommendations for future studies emphasised firstly the relevance of adequate sample sizes to determine the effects, and secondly, they recommend "real world settings" for the treatments like those of the regular psy chiatric health care centres.

The present study explored whether regular mental health professionals in a Western country successfully could treat trau matized refugees with granted asylum, but also asylum seekers. A naturalistic study was carried out to compare the efficacy of NET with the current TAU already offered in the generalized health care system. Finally, we wanted to explore the potential differences in treatment responses between refugees and asylum seekers.

\section{Method}

\section{Design and procedure}

This treatment study is a prospective, comparative randomized trial with three assessment points: pre test, i.e., before treatment, post test at one month after treatment, and a follow up at six months after termination.

The system of health care in Norway is decentralized; psychi atric services are offered in each municipality and supported by larger psychiatric hospitals and outpatient clinics. The participants were both refugees and asylum seekers who had been referred to treatment in the general psychiatric services in Mid Norway. Ref ugees $\left(\begin{array}{ll}N & 63\end{array}\right)$ and asylum seekers $\left(\begin{array}{ll}N & 41\end{array}\right)$ from different nations were screened before admission into the study. The inclusion criteria were: age above 18 years, and a PTSD diagnosis according to the DSM IV criteria. The exclusion criteria were psychotic disor ders, current severe substance abuse, or severe suicidal ideations. All the primary care physicians were made aware of inclusion in the project and the diagnose of PTSD for their patients. The study was approved by the Regional Committee for Medical Research Ethics in Mid Norway, and by the Norwegian Social Science Data Services. Moreover, the study is compliant with the Consort Clinical Trial Guidelines for Nonpharmacological Treatments (Boutron, Moher, Altman, Schulz, \& Ravaud, 2008).

Participants were randomized to the treatment conditions by drawing balls from a bag with an a priori $2 / 3$ chance of receiving NET and $1 / 3$ chance of receiving TAU. For the identification of predictors for the treatment outcome of NET, a larger sample size was aimed for in the NET group than in the TAU group. In accor dance with previous randomized controlled trials on NET (Ertl,

Table 1

Socio-demographic and clinical information of the 81 refugees and asylum seekers randomized to Narrative Exposure Therapy (NET) and to Treatment as Usual (TAU).

\begin{tabular}{|c|c|c|c|c|}
\hline & & $\begin{array}{l}\text { NET } \\
\left(\begin{array}{ll}n & 51\end{array}\right)\end{array}$ & $\begin{array}{l}\text { TAU } \\
\left(\begin{array}{ll}n & 30\end{array}\right)\end{array}$ & $p$ \\
\hline \multicolumn{5}{|l|}{ Demographic information } \\
\hline Gender & & & & n.s. \\
\hline Female & $N(\%)$ & $17(33 \%)$ & $8(27 \%)$ & \\
\hline Male & $N(\%)$ & $34(67 \%)$ & $22(73 \%)$ & \\
\hline Age & $M(S D)$ & $34.5(11.1)$ & $36.6(11.0)$ & n.s. \\
\hline Level of completed education & & & & n.s. \\
\hline No education & $N(\%)$ & $6(12 \%)$ & $2(7 \%)$ & \\
\hline Primary school & $N(\%)$ & $18(35 \%)$ & $9(29 \%)$ & \\
\hline Secondary school & $N(\%)$ & $15(29 \%)$ & $6(20 \%)$ & \\
\hline Vocational school & $N(\%)$ & $3(6 \%)$ & $2(7 \%)$ & \\
\hline University & $N(\%)$ & $9(18 \%)$ & $11(37 \%)$ & \\
\hline Months in exile & $M(S D)$ & $55.4(50.3)$ & $57.0(51.9)$ & n.s. \\
\hline Region of Origin & & & & n.s. \\
\hline Afghanistan & $N(\%)$ & $7(14 \%)$ & $5(17 \%)$ & \\
\hline Iraq & $N(\%)$ & $15(29 \%)$ & $7(23 \%)$ & \\
\hline $\begin{array}{l}\text { Middle East (remaining } \\
\text { countries) }\end{array}$ & $N(\%)$ & $8(16 \%)$ & $5(17 \%)$ & \\
\hline Africa & $N(\%)$ & $13(25 \%)$ & $8(26 \%)$ & \\
\hline Other countries & $N(\%)$ & $8(16 \%)$ & $5(17 \%)$ & \\
\hline Asylum seekers at pre-treatment & $N(\%)$ & $20(39 \%)$ & $11(37 \%)$ & n.s. \\
\hline Refugees at pre-treatment & $N(\%)$ & $31(61 \%)$ & $19(63 \%)$ & n.s. \\
\hline $\begin{array}{c}\text { Change of asylum status } \\
\text { during study period }\end{array}$ & & & & n.s. \\
\hline No change & $\%$ & $82 \%$ & $94 \%$ & \\
\hline $\begin{array}{l}\text { Change from asylum seeker } \\
\text { to granted asylum }\end{array}$ & $\%$ & $10 \%$ & $3 \%$ & \\
\hline $\begin{array}{l}\text { Change from asylum seeker } \\
\text { to denied asylum }\end{array}$ & $\%$ & $8 \%$ & $3 \%$ & \\
\hline \multicolumn{5}{|l|}{ Clinical Data at pre-treatment } \\
\hline $\begin{array}{l}\text { Number of traumatic event } \\
\left.\text { types(CAPS }{ }^{\mathrm{a}}\right)\end{array}$ & $M(S D)$ & $8.3(2.2)$ & $7.9(2.9)$ & n.s. \\
\hline CAPS $^{\text {a }}$ Score & $M(S D)$ & $83.7(15.5)$ & $83.67(16.5)$ & n.s. \\
\hline HAM-D ${ }^{\mathrm{b}}$ Score & $M(S D)$ & $19.7(7.4)$ & $21.6(6.4)$ & n.s. \\
\hline $\begin{array}{l}\text { Current Major Depressive } \\
\text { Episode }\end{array}$ & $\%$ & $20(41.7 \%)$ & $12(41.4 \%)$ & n.s. \\
\hline Medication & & & & n.s. \\
\hline Benzodiazepines & $N(\%)$ & $2(4 \%)$ & $1(3 \%)$ & \\
\hline Antidepressants & $N(\%)$ & $4(8 \%)$ & $5(17 \%)$ & \\
\hline Treatment completers & $N(\%)$ & $33(64 \%)$ & $21(70 \%)$ & n.s. \\
\hline
\end{tabular}

Note: For pair-wise group comparisons of continuous variables, $t$-tests for independent samples were used. Differences between categorical variables were assessed by Chi-square tests for independence.

a CAPS Clinician Administered PTSD Scale.

b HAM-D Hamilton Rating Scale for Depression. 
Pfeiffer, Schauer, Elbert, \& Neuner, 2011; Neuner et al., 2009; Neuner et al., 2004), a between treatment effect size (Cohen's d) of about 0.90 was expected and considered to be clinically signifi cant. For adequate analysis, complete data from 23 patients was aimed for in each group at the power level of p.b 0.90 (Chan, 2003). Assuming an attrition rate of $20 \%$, a final sample size of 30 was anticipated in each group. Previous studies for CBT and NET with PTSD have resulted in large effect sizes with samples of 30 patients per condition (Foa, Keane, Friedman \& Cohen, 2009; Robjant \& Fazel, 2010).

Assessments of the diagnostic status and the symptom severity were made by the group of 24 therapists from the 11 different treatment centers. No assessor ever assessed their own patients, and we always aimed for assessments to be undertaken by asses sors from different centers than where the patients received their treatment. The assessors had no access to information about what therapy the patients' had been assigned to, or to their previous assessments. The therapists were instructed not to reveal the type of treatment their patients were given. The aim was to make the assessors as blind as possible to the patients' treatments. In spite of these efforts, it appeared that in $11(20 \%)$ of 54 post tests, the pa tients had revealed information about their treatment to the as sessors. A statistical analysis showed no significant differences of these post tests from the other assessments. To ascertain high quality assessments, an experienced psychologist was present the first time each assessor administered the instruments, and also, the therapists were supervised on the assessment. If the patients were not reasonably fluent in Norwegian or English, certified translators assisted both in the assessments and in the treatments. Before entering the project, translators were briefed on how to contribute during the assessments and treatment sessions.

\section{Participants}

Eighty one of the 104 screened respondents (refugees $N \quad 50$; asylum seekers $N \quad 31)$ met the inclusion criteria. The majority were men ( $N \quad 56$, as compared to women $N \quad 25$ ), and they had completed primary or secondary school $\left(\begin{array}{ll}N & 48\end{array}\right)$. The mean age was 35 years. After having completed the orientation about the study, written informed consent was obtained. Table 1 shows the demographic and clinical data of the participants within the two treatment groups.

Fig. 1 shows the patient flow through the study, the enrollment, the randomization and the treatment allocations. All together, 54 patients completed both post test and the follow up interviews; they will be referred to as treatment completers. There were no significant differences between the intent to treat sample and the treatment completers with respect to age, gender, level of educa tion, time spent in exile, asylum status, HAM D scores, CAPS total scores, or their reported number of traumatic events.

Medication was not taken away before the start of the trial because requiring the patients to end their medications would have

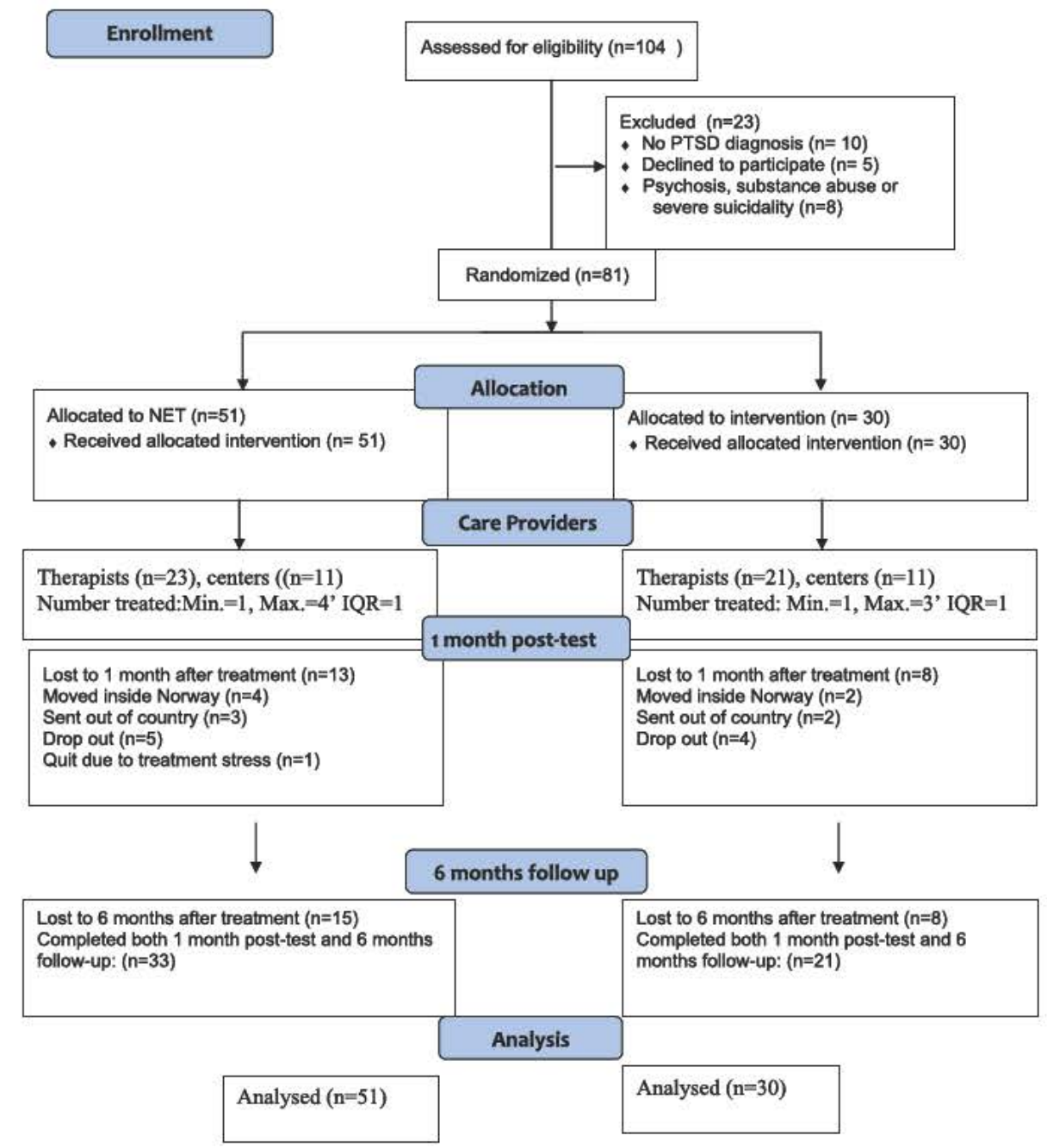

Fig. 1. CONSORT flow diagram of refugees and asylum seekers with PTSD through enrollment, randomization, and treatment. 
been unethical and could possibly lead to an increase in symp tomatology at baseline and inflate initial assessments. Twelve participants recounted regular use of psychotropic medications pre treatment. Four in the NET group and five in the TAU group used antidepressants. Moreover, two in the NET group and one in the TAU group used benzodiazepines. For the NET group, the medication remained unchanged during the treatment and the post tests, whereas the participants of the TAU group could have their medication changed during the project. None of the partici pants in the NET group and three of the participants in the TAU group reported changes in their medication from pre treatment to six months post treatment. Medication changes are not uncommon in regular treatments, like the TAU. In the TAU group, one patient used $30 \mathrm{mg}$ Mianserine and stopped taking it between one month posttest and six months follow up. One patient changed from Paroxetine ( $40 \mathrm{mg}$ ) to Chlorprothixine ( $45 \mathrm{mg}$ ) plus Escitalopram (15 mg), also between one month posttest and six months follow up. One patient started on Quetiapin during the treatment, but terminated prior to the posttest.

\section{Therapists}

Twenty four experienced mental health professionals at eleven centres in the general psychiatric services served as therapists. They were psychologists $\left(\begin{array}{ll}N & 9\end{array}\right)$, psychiatrist $\left(\begin{array}{ll}N & 1\end{array}\right)$, psychiatric nurses ( $N$ 9), occupational therapists $\left(\begin{array}{ll}N & 2\end{array}\right)$, drama therapist $\left(\begin{array}{ll}N & 1\end{array}\right)$, and clinical social workers $\left(\begin{array}{ll}N & 2\end{array}\right)$. All had been given specific training in the assessments and in the Narrative Exposure Therapy (i.e., a total of five days followed by supervision). Subse quently, the therapists attended two day supervision gatherings every six months to maintain their skills.

\section{Treatment}

Both treatment conditions consisted of 10 sessions of $90 \mathrm{~min}$ duration. The aim was to give one session per week. To rule out possible therapist effects, each therapist had both patients who were given the NET and the TAU. The therapists were given individual supervision after the patients' 1st, 4th, 6th and the 9th sessions, irrespective of what kind of therapy they gave. Treatment adherence in both conditions was monitored through supervision and through self report measures after each session. In the NET condition, the use of the main NET components was reported, and also, to what extent the session focused on exposure to memories of the traumatic events. In the TAU condition, the therapists specified their areas of focus, interventions, and the time spent on traumatic events.

NET was carried out according to the manual as outlined by Schauer et al. (2005) (second revised edition 2011). In the TAU condition, the therapists were instructed to use any intervention they normally would use, except for the steps specific to NET. From the supervision and the self reports, TAU mainly consisted of help with such as sleep problems, depressive symptoms, problems related to asylum status, and other practical matters. A mean of $86 \mathrm{~min}$ in the ten TAU sessions was spent on traumatic events and consisted mainly of overviews without further scrutiny of indi vidual events. The focus on everyday issues and the limited focus on the traumatic events in the TAU condition were in line with reports from the National Center on Violence and Traumatic Stress. The center had made a screening of what kinds of help that were offered to the traumatized survivors in Norway (Hjemdal, 2006).

\section{Measures}

The PTSD diagnosis and the PTSD symptom severity were determined by the Clinician Administered PTSD Scale - CAPS
(Blake et al., 1995). The CAPS total score is the sum of the 17 core symptoms. CAPS had been translated into Norwegian and back translated.

Depression was diagnosed with the MINI International Neuro psychiatric interview (Sheehan et al., 1998). It was also used to exclude possible comorbid DSM IV Axis I disorders such as psy chosis, substance abuse and suicidal ideations. The Hamilton Rating Scale for Depression - HAM D (Hamilton, 1960) was employed for symptom severity of depression. The main part of the scale consists of 17 items, the sum constitutes the HAM D score.

\section{Statistical analyses}

Following the recommendation of Hamer \& Simpson (Hamer \& Simpson, 2009) within an intention to treat analysis, data from all randomized patients were included in the final analyses. For the outcome variables, i. e., the CAPS total score and the HAM D score, mixed effect models were used; they utilize all available data. They included subject and treatment center as random effects, and treatment, time (changes from pre test to posttest and follow up), asylum status, Treatment $\times$ Time, Treatment $\times$ Asylum Status, Time $\times$ Asylum Status and Treatment $\times$ Time $\times$ Asylum Status as fixed effects, whereby the subjects were nested in treatment cen ters and treatments. The treatment effects were estimated by calculating the within and the between treatment effects sizes (Hedges' g) for the CAPS total scores and for the HAM D scores. In contrast to Multiple Imputation or LOCF, the mixed effect model does not impute any missing cases, - and therefore, this approach does not provide a distribution of the Intention to treat scores that could be the basis for the estimations of effect sizes. As a conse quence, the effect sizes are necessarily restricted to the treatment completers. In order to test for possible changes in the diagnostic status of PTSD from pre test to post test, and further on, to the follow up, chi square tests were used. In addition to group level analyses, decline or increase in PTSD symptom severity was explored at the individual level and based on the data available from the treatment completers. Following the suggestion by Jacobson and Truax, 1991, a fall in the CAPS total scores was considered clinically significant if the changes from pre test to follow up exceeded two standard deviations in the initial pre test distribution. The main effects of treatment and the interaction term were judged at an alpha level of 0.05 (two sided).

\section{Results}

\section{Changes in symptom severity}

For the CAPS total scores (Fig. 2), a significant main effect of time, $\mathrm{F}(2,121.3) \quad 30.11, p<.0001$, a main effect of treatment, $\mathrm{F}(1$, 71.1) $\quad 4.44, p<.05$, and a significant Time $\times$ Treatment interac tion, $\mathrm{F}(2,122.5) \quad 7.55, p<.001$ were found. No significant effects were found for gender, asylum status or treatment center.

The mixed model calculated for the HAM D scores resulted in a significant main effect of time, $\mathrm{F}(2,114.2) \quad 11.64, p<.0001$ and a main effect of asylum status, $\mathrm{F}(1,63.21) \quad 4.13, p<.05$. Refugees showed lower depression scores at all time points compared to the asylum seekers. The interaction Asylum Status $\times$ Treatment was not significant for depression and also, no significant main effects were found for the asylum status and for the kind of treatment.

Table 2 shows the within groups effect sizes (Hedges' g) of the decline in the PTSD symptom severity and in the levels of depres sion for the refugees and the asylum seekers.

For the refugees at the six months follow up, the effect size of the between group (NET vs. TAU) for the CAPS scores was 0.77 [confidence interval: $0.07,1.47$ ]. The asylum seekers had a between 


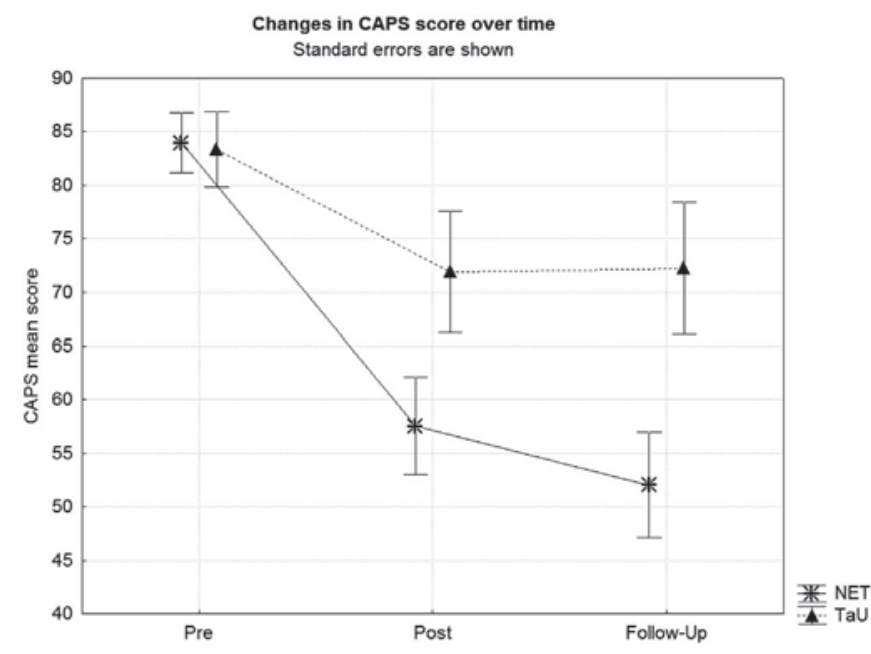

Fig. 2. CAPS ${ }^{\mathrm{a}}$ total scores before treatment, at 1 month post-test, and at 6 months follow-up of patients treated with $\mathrm{NET}^{\mathrm{b}}\left(\begin{array}{lll}N & 33\end{array}\right)$, and $\mathrm{TAU}^{\mathrm{c}}\left(\begin{array}{ll}N & 21\end{array}\right)$. Only treatment completers are included. ${ }^{a}$ CAPS Clinician Administered PTSD Scale. ${ }^{b}$ NET Narrative Exposure Therapy. ${ }^{\mathrm{C}} \mathrm{TAU}$ Treatment As Usual.

group effect size of 0.58 (confidence interval: $0.37,1.53$ ). The between group effect size (NET vs. TAU) for the HAM D scores at six months follow up was 0.52 [confidence interval: $0.17,1.21$ ] for the refugees, and for the asylum seekers, it was 0.59 (confidence interval: $0.36,1.54]$.

\section{Changes of diagnostic status}

At the six month follow up, $54.5 \%$ of the participants in the NET group met the criteria for the PTSD diagnosis compared to $81 \%$ in the TAU group (chi2 $p<.05$ ). The changes of the PTSD diagnostic status at one and six months after termination of treatment are displayed in Table 3.

In the NET group, $50 \%$ of those with a diagnosis of major depression before treatment had lost their diagnostic status at the six months follow up. In the TAU group, 26.3\% had lost their diagnostic status at the six months follow up (chi2 $p<.1$ ).

\section{Change of scores in individuals}

A clinically significant decrease in the CAPS scores was observed in $64 \%(N \quad 20)$ of the participants in the NET group, as compared to only $4.3 \%\left(\begin{array}{ll}N & 1\end{array}\right)$ in the TAU group. Six patients who received the TAU and four NET patients were found to increase their PTSD symptom levels at the six months follow up. The changes, however, did not reach the threshold of reliable change. Fig. 3 shows a scatter plot of the individual scores of the treatment completers from pre treatment to follow up.

\section{Discussion}

The present study demonstrates that both refugees and asylum seekers reduced their mental health problems related to PTSD and depression by the treatment provided by the general psychiatric services. The symptom reductions in PTSD and depression were more pronounced in the patients who received NET. Refugees with a secure legal status reported less depression across all time points. However, both asylum seekers and refugees profited from the treatment to the same degree in spite of their differences at the outset with regard to the symptom levels.

Likewise, the groups of refugees and asylum seekers who were given NET, emerged with a bigger fall in diagnostic status for PTSD than those who were given TAU. This decline is similar to what has been found for specific cognitive behavioural approaches given to refugees with PTSD (Hinton et al., 2005; Paunovic \& Ost, 2001), and also, it is similar to the effects found for NET in low and middle income countries with patient populations of diverse trauma ex posures. From the Western countries, only one study by Neuner and colleagues has specifically compared NET and TAU in asylum seekers with PTSD (Neuner et al., 2009). In general, our findings concur with their main results. Both studies found NET to be su perior to TAU in reducing PTSD symptom severity. Also, both studies showed a slight decline in PTSD symptom severity in the TAU group. In the Neuner study, all but one person in the NET group and all in the TAU group kept their PTSD diagnoses after the six months follow up. In our study, almost half the NET group did not meet the diagnostic criteria for PTSD at the six months follow up, while about one fifth showed such decline in the TAU group. Some caution is warranted in interpreting these findings for the group of asylum seekers. More asylum seekers in the NET (10\%) than in the TAU group (3\%) were formally accepted as refugees during the course of the therapy; this may in part account for some of the differences in the trajectories of the two groups (Davis \& Davis, 2006; Silove et al., 2007). That the superiority of the NET for asylum seekers was not observable before at the six months follow up may support this interpretation. However, the opposite effect occurred for rejection rates, with more subjects having ap plications declined in the NET (8\%) than in the TAU (3\%) group. As the number of subjects is too small to isolate the effects of the changes of legal status within this trial it remains unclear whether the opposing effects of acceptance and rejection swayed the outcome in any direction.

With regard to depression, both NET and TAU had moderate treatment effects. According to the supervisors and therapists' self reports, depressive symptoms were targeted in many TAU

Table 2

Within-group effect sizes (Hedges' $\mathrm{g}$ and $95 \%$ confidence intervals in brackets) of CAPS ${ }^{\mathrm{a}}$ total scores (PTSD) and HAM-D ${ }^{\mathrm{b}}$ scores (depression) displayed separately for all refugees $\left(\begin{array}{ll}n & 35\end{array}\right)$ and for all asylum seekers $\left(\begin{array}{ll}n & 19\end{array}\right)$ who had completed their treatments.

\begin{tabular}{|c|c|c|c|c|c|}
\hline & \multicolumn{2}{|l|}{$\mathrm{NET}^{\mathrm{c}}\left(\begin{array}{ll}n & 33\end{array}\right)$} & \multicolumn{3}{|l|}{$\mathrm{TAU}^{\mathrm{d}}\left(\begin{array}{ll}n & 21\end{array}\right)$} \\
\hline & Refugees ( $n$ & Asylum seekers ( $n$ & Refugees $(n$ & Asylum seekers ( $n$ & 7) \\
\hline \multicolumn{6}{|l|}{ CAPS $^{\text {a }}$ total score } \\
\hline Within-group effect size ${ }^{\mathrm{e}}$ ( 1 month after treatment) & $1.37[0.70,2.04]$ & $0.90[0.06,1.74]$ & $0.42[-0.33,1.16]$ & \multicolumn{2}{|l|}{$0.82[-0.28,1.91]$} \\
\hline $\begin{array}{l}\text { Within-group effect size (6 months after treatment) } \\
\text { HAM-D }{ }^{\mathrm{b}} \text { score }\end{array}$ & $1.53[0.85,2.22]$ & $0.93[0.09,1.77]$ & $0.57[-0.19,1.33]$ & \multicolumn{2}{|l|}{$0.31[-0.75,1.36]$} \\
\hline Within-group effect size ( 1 month after treatment) & $0.89[0.26,1.52]$ & $0.72[-0.11,1.54]$ & \multirow{2}{*}{$\begin{array}{l}0.60[-0.16,1.36] \\
0.57[-0.18,1.33]\end{array}$} & \multicolumn{2}{|l|}{$1.10[-0.03,2.22]$} \\
\hline Within-group effect size (6 months after treatment) & $1.07[0.42,1.71]$ & $0.31[-0.49,1.12]$ & & $-0.32[-1.37,0.74]$ & \\
\hline
\end{tabular}

\footnotetext{
a CAPS Clinician Administered PTSD Scale.

b HAM-D Hamilton Rating Scale for Depression.

c NET Narrative Exposure Therapy.

d TAU Treatment As Usual.
}

e Hedges' $g$ (and confidence intervals in brackets) are shown. 
Table 3

Frequencies and percentage of patients with PTSD diagnoses and with current Major Depression (MD) before treatment, at one month and at six months after treatment (treatment completers).

\begin{tabular}{|c|c|c|c|c|c|}
\hline & \multicolumn{2}{|c|}{$\begin{array}{l}\text { Narrative Exposure } \\
\text { Therapy } \\
\end{array}$} & \multicolumn{2}{|c|}{ Treatment as usual } & \multirow[t]{2}{*}{$p$-values } \\
\hline & PTSD & No PTSD & PTSD & No PTSD & \\
\hline Before treatment & $33(100 \%)$ & $0(0 \%)$ & $21(100 \%)$ & $0(0 \%)$ & \\
\hline $\begin{array}{l}1 \text { month after } \\
\text { treatment }\end{array}$ & $19(57.6 \%)$ & $14(42.4 \%)$ & $14(66.7 \%)$ & $7(33.3 \%)$ & $\begin{array}{ll}\chi^{2} & 0.45 \\
p & .50\end{array}$ \\
\hline \multirow[t]{3}{*}{$\begin{array}{c}6 \text { months after } \\
\text { treatment }\end{array}$} & $18(54.5 \%)$ & $15(45.5 \%)$ & 17 (81\%) & $4(19 \%)$ & $\begin{array}{l}\chi^{2} \quad 3.92, \\
p<.05\end{array}$ \\
\hline & \multicolumn{2}{|c|}{$\begin{array}{l}\text { Narrative Exposure } \\
\text { Therapy }\end{array}$} & \multicolumn{2}{|c|}{ Treatment as usual } & $p$-values \\
\hline & PTSD & No PTSD & PTSD & No PTSD & \\
\hline Before treatment & $27(81.9 \%)$ & $6(18.1 \%)$ & $18(85.7 \%)$ & $3(14.3 \%)$ & \\
\hline $\begin{array}{l}1 \text { month after } \\
\text { treatment }\end{array}$ & $16(48.5 \%)$ & $16(48.5 \%)$ & $13(61.9 \%)$ & $8(38.1 \%)$ & $\begin{array}{ll}\chi^{2} & 0.54 \\
p & .46\end{array}$ \\
\hline $\begin{array}{l}6 \text { months after } \\
\text { treatment }\end{array}$ & $16(48.5 \%)$ & $17(51.5 \%)$ & $14(73.7 \%)$ & $7(26.3 \%)$ & $\begin{array}{ll}\chi^{2} & 2.76, \\
p & .10\end{array}$ \\
\hline
\end{tabular}

treatments. NET has been specifically developed for the treatment of PTSD, but some studies have shown that the approach may also have effects on depression (Catani et al., 2009; Schaal, Elbert \& Neuner, 2009). As symptoms of depression may be instigated by traumatic stress, it is not surprising that NET may reduce the levels of depression. At all times, the asylum seekers had significantly higher levels of depression in the assessments compared to the refugees. High frequencies of depression among asylum seekers are consistent with the findings of others, which may be an indication of the burden related to being an asylum seeker in the Western countries (Gorst Unsworth \& Goldenberg, 1998; Steel et al., 2006).

The possible outcome difference between refugees and asylum seekers was also a focus in our study. The prevalent view in most Western countries has been that asylum seekers are too unstable to benefit from treatment of PTSD. This is based on the assumption that individuals need to feel safe and secure before specific trauma focused therapy will be effective. As the legal procedures of asylum seeking in many countries tend to drag on for years, a vast number of the asylum seekers spend considerable time in unstable situa tions. The fear of being sent out of the country by force is prevalent

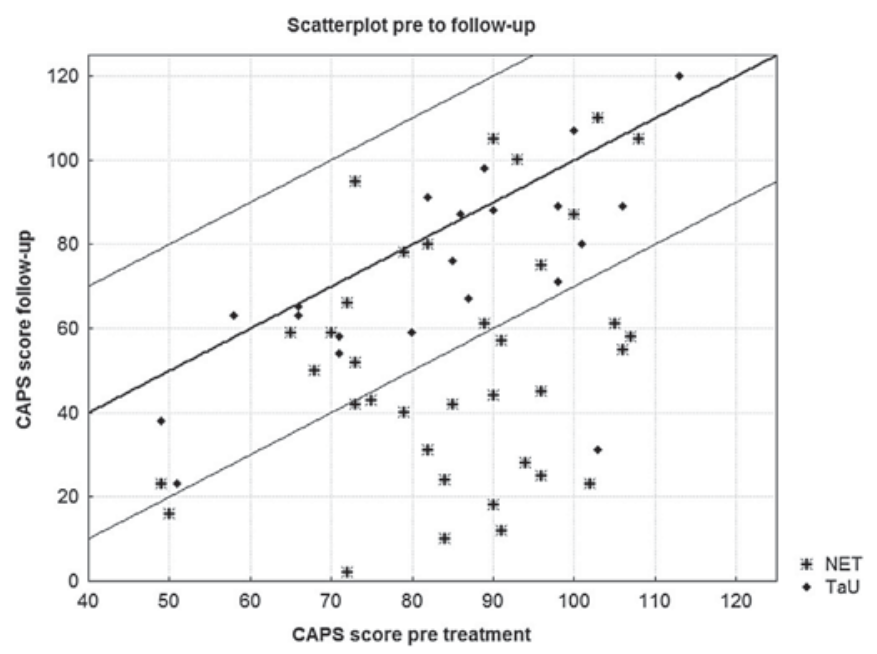

Fig. 3. Scatterplot of individual CAPS ${ }^{\mathrm{a}}$ total scores before treatment and at 6 months follow-up of patients treated with $\mathrm{NET}^{\mathrm{b}}\left(\begin{array}{lll}N & 33\end{array}\right)$, and $\mathrm{TAU}^{\mathrm{c}}\left(\begin{array}{ll}N & 21\end{array}\right)$. Only treatment completers are included. ${ }^{\mathrm{a}} \mathrm{CAPS}$ Clinician Administered PTSD Scale. ${ }^{\mathrm{b}} \mathrm{NET}$ Narrative Exposure Therapy. ${ }^{\mathrm{C}} \mathrm{TAU}$ Treatment As Usual. in most asylum seekers, and this fear is a major threat for all asylum seekers in Norway; about half of them get their applications denied. To an increasing degree forced repatriation is used (UDI, 2012). Surprisingly, our results showed no difference between refugees and asylum seekers in the treatment outcomes. One explanation may be that the structure of the NET sessions is easy to grasp. Both patients and therapists understand that the focus is on the person's traumatic life history. Concurrent difficulties and avoidance of trauma issues that otherwise easily impede the work with asylum seekers, are therefore less likely to interfere. There were only 31 asylum seekers, and caution is needed in the interpretation of the relevance of the asylum status. Our data indicate that a consider able effect is unlikely to stem from the asylum status on treatment success. In agreement with the pilot study of Neuner et al. (2009), the notion that asylum seekers are unable to benefit from treat ment of PTSD did not gain support in this study.

\section{Limitations of study}

The study was carried out without videotaping the treatment sessions. For logistical reasons, a complete blinding of some of the post tests could not be achieved. The heterogeneity of the refugees and asylum seekers originating from many regions and cultures, have made the findings harder to interpret. In the same vein, about half the assessments and treatments required assistance by in terpreters and assessment tools were not validated to the language and culture of each asylum seeker or refugee. The differences in the original background training of the therapists, may also have added to the diversity. Together such factors are likely to have reduced some of the effect size in the outcome. Nevertheless, it should also be noted that such factors would be encountered in any practical treatment situation with these populations. Accordingly, the effect size of this study may reflect treatment outcome in the real world.

\section{Conclusions}

Even though refugees and asylum seekers with PTSD used to be considered difficult to treat, our findings indicate that when given adequate treatment, many will improve. NET seems a straightfor ward, promising therapeutic approach which may be provided by several professions in the general health services. This study also indicates that for PTSD in refugees and asylum seekers, NET is significantly more effective than TAU.

\section{Acknowledgements}

This project has been financially supported by the Norwegian Council For Mental Health and the Norwegian Extra Foundation for Health and Rehabilitation.

\section{References}

Birck, A. (2001). Torture victims after psychotherapy: a two-year follow up. Torture, 11,5158

Birck, A. (2004). Symtomatik bei kriegs- und folteruberlebenden Fluchtlingen, mit und ohne Psychotherapie (Syptoms in refugees who survived torture or war with and without psychotherapy). Zeitsschrift for klinische Psychologie und Psychotherapie, 33, 101109.

Blake, D. D., Weathers, F. W., Nagy, L. M., Kaloupek, D. G., Gusman, F. D., Charney, D. S., et al. (1995). The development of a clinician-administered PTSD scale. Journal of Traumatic Stress, 8(1), 7590.

Boutron, I., Moher, D., Altman, D. G., Schulz, K. F., \& Ravaud, P. (2008). Methods and processes of the CONSORT Group: example of an extension for trials assessing nonpharmacologic treatments. Annals of Internal Medicine, 148(4), W60 W66.

Carlsson, J. M., Mortensen, E. L., \& Kastrup, M. (2005). A follow-up study of mental health and health-related quality of life in tortured refugees in multidisciplinary treatment. Journal of Nervous and Mental Disease, 193(10), 651657.

Catani, C., Kohiladevy, M., Ruf, M., Schauer, E., Elbert, T., \& Neuner, F. (2009). Treating children traumatized by war and Tsunami: a comparison between 
exposure therapy and meditation-relaxation in North-East Sri Lanka. BMC Psychiatry, 9, 22.

Chan, Y. H. (2003). Randomized controlled trials (RCTs)-Sample size: the magic number? Singapore Medical Journal, 44(4), 172174.

Davis, R. M., \& Davis, H. 4th (2006). PTSD symptom changes in refugees. Torture, 16(1), 1019.

Ertl, V., Pfeiffer, A., Schauer, E., Elbert, T., \& Neuner, F. (2011). Community-implemented trauma therapy for former child soldiers in Northern Uganda: a randomized controlled trial. Journal of the American Medical Association, 306(5), 503512.

Fazel, M., Wheeler, J., \& Danesh, J. (2005). Prevalence of serious mental disorder in 7000 refugees resettled in western countries: a systematic review. Lancet, 365(9467), 13091314.

Foa, E., Keane, T., Friedman, M. J., \& Cohen, J. A. (2009). Effective treatments for PTSD: Practice guidelines from the International Society for Traumatic Stress Studies. The Guilford Press.

Gorst-Unsworth, C., \& Goldenberg. E. (1998). Psychological sequelae of torture and organised violence suffered by refugees from Iraq. Trauma-related factors compared with social factors in exile. British Journal of Psychiatry, 172, 9094.

Halvorsen, J. O., \& Stenmark, H. (2010). Narrative exposure therapy for posttraumatic stress disorder in tortured refugees: a preliminary uncontrolled trial. Scandinavian Journal of Psychology.

Hamer, R. M., \& Simpson, P. M. (2009). Last observation carried forward versus mixed models in the analysis of psychiatric clinical trials. American Journal of Psychiatry, 166(6), 639641.

Hamilton, M. (1960). A rating scale for depression. Journal of Neurology, Neurosurgery, and Psychiatry, 23, 5662.

Hinton, D. E., Chhean, D., Pich, V., Safren, S. A., Hofmann, S. G., \& Pollack, M. H. (2005). A randomized controlled trial of cognitive-behavior therapy for Cambodian refugees with treatment-resistant PTSD and panic attacks: a crossover design. Journal of Traumatic Stress, 18(6), 617629.

Hjemdal, O. K. (2006). Kartlegging av tilbudet til traumatiserte ofre for vold, overgrep, ulykker og katastrofer, flyktninger og torturofre.

Jacobson, N. S., \& Truax, P. (1991). Clinical significance: a statistical approach to defining meaningful change in psychotherapy research. Journal of Consulting and Clinical Psychology, 59(1), 1219.

Neuner, F., Kurreck, S., Ruf, M., Odenwald, M., Elbert, T., \& Schauer, M. (2009). Can asylum-seekers with posttraumatic stress disorder be successfully treated? A randomized controlled pilot study. Cognitive Behaviour Therapy, 39(2), 8191.

Neuner, F., Schauer, M., Klaschik, C., Karunakara, U., \& Elbert, T. (2004). A comparison of narrative exposure therapy, supportive counseling, and psychoeducation for treating posttraumatic stress disorder in an african refugee settlement. Journal of Consulting and Clinical Psychology, 72(4), 579587.

Nickerson, A., Bryant, R. A., Silove, D., \& Steel, Z. (2011). A critical review of psychological treatments of posttraumatic stress disorder in refugees. Clinical Psychology Review, 31(3), 399417.

Otto, M. W., Hinton, D., Korbly, N. B., Chea, A., Ba, P., Gershuny, B. S., et al. (2003). Treatment of pharmacotherapy-refractory posttraumatic stress disorder among
Cambodian refugees: a pilot study of combination treatment with cognitivebehavior therapy vs sertraline alone. Behaviour Research and Therapy, 41(11), 12711276.

Paunovic, N., \& Ost, L. G. (2001). Cognitive-behavior therapy vs exposure therapy in the treatment of PTSD in refugees. Behaviour Research and Therapy, 39(10), 11831197.

Porter, M., \& Haslam, N. (2005). Predisplacement and postdisplacement factors associated with mental health of refugees and internally displaced persons: a meta-analysis. Journal of the American Medical Association, 294(5), 602612.

Robjant, K., \& Fazel, M. (2010). The emerging evidence for Narrative Exposure Therapy: a review. Clinical Psychology Review, 30(8), 10301039.

Schaal, S., Elbert, T., \& Neuner, F. (2009). Narrative exposure therapy versus interpersonal psychotherapy. A pilot randomized controlled trial with Rwandan genocide orphans. Psychotherapy and Psychosomatics, 78(5), 298306.

Schauer, M., Neuner, F., \& Elbert, T. (2005). Narrative exposure therapy: A short-term intervention for traumatic stress disorders after war, terror and torture. Gottingen, Germany: Hogrefe \& Huber.

Sheehan, D. V., Lecrubier, Y., Sheehan, K. H., Amorim, P., Janavs, J., Weiller, E., et al. (1998). The Mini-International Neuropsychiatric Interview (M.I.N.I.): the development and validation of a structured diagnostic psychiatric interview for DSM-IV and ICD-10. Journal of Clinical Psychiatry, 59(Suppl 20), 22 33. quiz 3457.

Silove, D., Steel, Z., Susljik, I., Frommer, N., Loneragan, C., Chey, T., et al. (2007). The impact of the refugee decision on the trajectory of PTSD, anxiety, and depressive symptoms among asylum seekers: a longitudinal study. American Journal of Disaster Medicine, 2(6), 321329.

Sinnerbrink, I., Silove, D., Field, A., Steel, Z., \& Manicavasagar, V. (1997). Compounding of premigration trauma and postmigration stress in asylum seekers. Journal of Psychology, 131(5), 463470.

Steel, Z., Chey, T., Silove, D., Marnane, C., Bryant, R. A., \& van Ommeren, M. (2009). Association of torture and other potentially traumatic events with mental health outcomes among populations exposed to mass conflict and displacement: a systematic review and meta-analysis. Journal of the American Medical Association, 302(5), 537549.

Steel, Z., Momartin, S., Silove, D., Coello, M., Aroche, J., \& Tay, K. W. (2011). Two year psychosocial and mental health outcomes for refugees subjected to restrictive or supportive immigration policies. Social Science \& Medicine, 72(7), 11491156.

Steel, Z., Silove, D., Brooks, R., Momartin, S., Alzuhairi, B., \& Susljik, I. (2006). Impact of immigration detention and temporary protection on the mental health of refugees. British Journal of Psychiatry, 188, 5864.

Toar, M., O'Brien, K. K., \& Fahey, T. (2009). Comparison of self-reported health \& healthcare utilisation between asylum seekers and refugees: an observational study. BMC Public Health, 9, 214.

Turner, S. W., Bowie, C., Dunn, G., Shapo, L., \& Yule, W. (2003). Mental health of Kosovan Albanian refugees in the UK. British Journal of Psychiatry, 182, 444448.

UDI. (2012). Yearly report 2011. from http://www.udi.no/Norwegian-Directorate-ofImmigration/. 